\title{
Aprendre a la ciutat \\ A TRAVÉS DE LA DERIVA
}

\author{
M. Mar Estrela Cerveró \\ Universitat de València
}

\section{Jaume Martínez Bonafé \\ Universitat de València}

RESUM: La deriva ha estat la inspiració i el camí per a profunditzar en l'aprenentatge que suposa caminar la ciutat. Els passos que anàvem donant ens han portat a replantejar-nos diferents aspectes educatius que transcendeixen les nostres pretensions inicials. Partim dels estudis crítics i postcrítics del currículum, i així, a poc a poc, hem anat aproximant-nos a la recerca, la pedagogia o la didàctica. Tota aquesta experiència gira al voltant del taller «Educar la mirada/Documentar la ciutat» amb el qual hem caminat per diferents indrets de la nostra ciutat, al costat del professorat i l'alumnat de diferents estudis de grau de les universitats valencianes. Volem pensar la ciutat a través del subjecte que l'habita i que d'alguna manera la interpreta, examinant-la com una forma material de la cultura, és a dir, un dispositiu cultural del qual emergeixen missatges i significats, on es construeixen $i$ es desconstrueixen experiències, alimentant relats, formant i transformant biografies.

Paraules clau: deriva, currículum, universitat, ciutat.

RESUMEN: La deriva ha sido la inspiración y el camino para profundizar en el aprendizaje que supone caminar la ciudad. Los pasos que íbamos dando nos han llevado a replantearnos diferentes aspectos educativos que trascienden nuestras pretensiones iniciales. Partimos de los estudios críticos y poscríticos del currículo, y así, poco a poco, hemos ido aproximándonos a la investigación, la pedagogía o la didáctica. Toda esta experiencia gira alrededor del taller «Educar la mirada/Documentar la ciudad» con el que hemos caminado por 
diferentes lugares de nuestra ciudad, al lado del profesorado y del alumnado de diferentes estudios de grado de las universidades valencianas. Queremos pensar la ciudad a través del sujeto que la habita y que de alguna manera la interpreta, examinándola como una forma material de la cultura, es decir, un dispositivo cultural del que emergen mensajes y significados, donde se construyen y se deconstruyen experiencias, alimentando relatos, formando y transformando biografías.

Palabras clave: deriva, currículo, universidad, ciudad.

ABSTRACT: Wandering was the inspiration and the way to explore the learning that walking the city involves. The steps we took led us to rethink various aspects of education that went beyond our initial aims. Starting from critical and post-critical studies of the curriculum, we gradually moved towards research, pedagogy or didactics. This whole experience revolves around the "educate the gaze / document the city workshop" in which we have walked around different parts of our city, together with the teachers and students from various degrees in Valencian universities. Our aim is to think about the city through the eyes of someone who lives there and who interprets it in some way, examining it as a material form of culture, that is, a cultural device from which messages and meanings emerge, where experiences are constructed and deconstructed, fuelling stories, forming and transforming biographies.

KEYWORDS: wandering, curriculum, university, city.

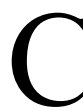
ada dia eixim al carrer i caminem d'un costat a un altre, però poques vegades ens donem l'oportunitat de convertir aquest acte quotidià en una experiència d'aprenentatge, a través de la qual pensar-nos a nosaltres mateixos i pensar el lloc en què ens trobem. I encara que no parem atenció, formem part d'un model social que anem conformant amb les estructures i formes de relació que establim quotidianament (Delgado, 2007, 2011). És per tot açò que es fa necessari pensar sobre el nostre aprenentatge al voltant de la ciutat, fent-nos conscients dels continus processos culturals que estructuren la nostra vivència (Martínez Bonafé, 2010). I quan ens referim a la ciutat, parlem del complex cultural que suposa la metròpoli contemporània, 
i per tant parlem de la seua estructura física, però sobretot del seu imaginari. Amb això ens acostem a la idea del currículum de la ciutat, és a dir, al reconeixement de la ciutat com un espai en el qual es conjuguen sabers i experiències que es representen als seus carrers i places, però també a les seues dinàmiques, tradicions i narratives, els quals ens construeixen com a ciutadans. Per això, el nostre punt de mira ha estat encreuar quotidianitat $i$ experiència educativa, obrint-nos a l'espai públic amb temps suficient per a contemplar-lo, pensar-lo i subjectivar-lo. En aquest sentit, la deriva ha sigut l'element que ens permetrà articular les nostres pretensions; així, la imatge del Flâneur de Baudelaire, sàviament recuperada per Walter Benjamin (1983), ens aporta una particular manera d'experimentar en la ciutat, a través d'un passeig sense rumb prefixat, amb el qual poder construir i desconstruir significats en relació a la ciutat. Es tracta de posar la ciutat concebuda entre parèntesis, per activar una forma d'ocupació de l'espai urbà, on l'ordre i la pretensió urbanística es queden paralitzades, en pro d'una nova òptica a través de la qual obrir-nos a l'experiència urbana.

Amb la intenció d'investigar la relació entre ciutat i currículum vam crear el taller «Educar la mirada/Documentar la ciutat» amb el qual portem quatre anys convidant a caminar els alumnes de diferents titulacions de les universitats de la nostra ciutat. En primer lloc, volem profunditzar en el paper del fenomen urbà en la construcció de les societats modernes, pensant la ciutat $\mathrm{i}$ el que d'aquesta es desprèn com un problema curricular lligat a la nostra experiència urbana i a la nostra tradició pedagògica. Tot això s'emmarca en una investigació més àmplia en tornar a la ciutat des dels estudis del currículum. I en segon lloc, ens plantegem la necessitat de generar activitats d'obertura de la universitat al context en què es troba, provocant un trencament amb el procés generalitzat de tancament i privatització de l'educació superior (Santos, 2004), explorant les possibilitats reals de mantenir un contacte estret amb la realitat que permeta l'experiència en primera persona i ens vincule als moviments socials $\mathrm{i}$ a les noves dinàmiques participatives que s'estan generant en la metròpoli.

En el marc dels estudis del currículum i des de les anàlisis crítiques i postcrítiques (Tadeu da Silva, 2001) ens enfrontem al contingut de la ciutat posant en crisi la seua fragmentació en disciplines, posant-lo en acció a través 
de l'experiència del món viscut (Contreras i Lara, 2010), atenent el seu sentit i les seues intersubjectivitats (Van Manen, 2003). Per la qual cosa els nous enfocaments transdisciplinars (Morín, 1994) ens suposen un marc amb el qual abastar la complexitat de les realitats modernes. Així, podem veure com la ciutat esdevé el resultat d'un procés de creació i interpretació social, per tant, seguint els estudis culturals, necessitem desconstruir els processos pels quals naturalitzem les nostres concepcions i pràctiques sobre la ciutat. Partint d'aquestes dues premisses, hem vist la necessitat de generar un nou currículum universitari que ens permeta posar en relació diferents disciplines al voltant de problemes situats en la realitat i en el territori. Amb la finalitat de poder abordar la complexitat estructural i el polimorfisme que caracteritza les realitats modernes centrarem la nostra mirada en la manera en què aprenem i actuem als carrers i quins són els processos culturals que estructuren aquesta vivència, per a poder veure més enllà del que la quotidianitat ens amaga (Debord, 1999).

El format actual del taller es realitza amb alumnes de grau de diferents titulacions i universitats, i s'inicia acotant un espai urbà de la ciutat (en el nostre cas, un barri de la ciutat de València: Russafa, Cabanyal, Orriols, Velluters, Benimaclet, Campanar, Sant Marcel·lí...) concretant un lloc on trobar-nos i partir, i al qual poder tornar després de dues o tres hores de passeig (normalment hem fet ús dels espais de col·lectius i associacions locals). Els grups, sovint nombrosos, es divideixen en altres més petits de no més de cinc persones. Cada xicotet grup es compon d'alumnes de diferent procedència acadèmica, i va prenent el seu rumb, allunyant-se i creuant-se amb els altres, caminant a la deriva per allò que el barri els pot oferir, entenent el passeig més enllà d'una visita, sent més prompte una oportunitat per a deixar-nos dur per la intuïció i el desig col·lectiu, en el traçat psicogeogràfic de noves trajectòries i experiències. Cadascú observa i comenta el que troba significatiu, allò que el sorprèn o provoca, emprant tota la capacitat dels seus sentits i el seu pensament, sense l'obligació d'apuntar res, però amb la complicitat d'un quadern que puga guardar la nostra necessitat expressiva. A l'hora fixada tornem a l'espai en què ens havíem citat i fem una posada en comú de l'experiència per part de tots els participants. Allí comentem l'experiència viscuda, ampliant les nostres percepcions a través de les diferents mirades interpretatives per a, finalment, escriure individualment la nostra experiència, acompanya- 
da si es vol de qualsevol altre recurs visual, component així El llibre de la ciutat. Actualment estem treballant en la construcció d'un blog que a més de contenir els textos puga servir com a espai de comunicació i construcció col-lectiva.

En definitiva, prenem la deriva situacionista com a font d'inspiració i la psicogeografia com a aspiració simbòlica, amb la intenció de generar noves representacions sobre la ciutat i provocar una relació subversiva amb la vida diària en la ciutat contemporània (Debord, 2000). Fem una aposta política per les ciutats per a promoure transformacions, amb la convicció que tots tenim alguna cosa a aportar, és a dir, creiem que en aquest procés l'experiència de tots no sols és valuosa, sinó necessària (Freire, 1970) i ens converteix (als investigadors i participants) en actors principals del canvi al voltant als elements centrals de les nostres vides.

La realitat és que cada curs ens enfrontem amb el repte de continuar convocant passejos a través del professorat participant que planteja l'activitat des de les seues assignatures. Tasca d'organització que no resulta fàcil, ja que cal trobar una vesprada on es puga generar un grup d'almenys vint persones. No obstant això, continuem fent-ho amb tota la il·lusió de seguir trobant racons nous en la nostra ciutat i redescobrint els barris que la confegeixen. En definitiva, volem reapropiar-nos de l'espai públic amb interès d'habitar-lo, des d'un enfocament educatiu crític, bàsic per a una nova ciutadania global. D'altra banda, cal dir que el taller està tenint molt bona acceptació entre els professors a qui convidem a participar, generant un grup cada vegada més nombrós de participants interessats. L'alumnat també s'ha mostrat molt receptiu amb la proposta, ja que per a ells tampoc és fàcil trobar contextos en la universitat en els quals treballar al costat de professors i d'investigadors en un pla horitzontal per a construir el seu propi coneixement de la ciutat, propiciant una experiència amb la qual aprendre a mirar $\mathrm{i}$ abastar la complexitat de la vida quotidiana al carrer. Amb la deriva caminem d'una altra manera, activant una mirada que vol trobar, una mirada sensible que penetra en la nostra experiència a través dels afectes. Tot això ens ajuda a traspassar la superficialitat amb què sovint caminem, per a començar a parlar de i des de el que a nosaltres ens passa. 
La realitat ens provoca des del moment en què és captada significativament, i això ens porta a parlar-ne, a ordenar el nostre pensament i expressar-nos. Novament, això suposa un trencament amb la tradició educativa dominant que sotmet l'experiència al relat individual o al silenci. Per tant, el nostre posicionament aposta clarament per la creació d'espais educatius a la ciutat amb els quals posar en relació les persones a través del diàleg, i creiem que el taller pot ajudar, tant a institucions com a moviments socials en el context de la intervenció sociocultural. Per tant, no sols es tracta d'una activitat acadèmica, o didàctica a la universitat, sinó que s'emmarca en una concepció extensa del concepte d'educació que ha de connectar amb els espais de vida, i que per tant pot ser pensada i adaptada per a qualsevol edat. De fet, en realitzacions anteriors al model actual del taller, s'ha desenvolupat amb alumnes de diferents instituts de la ciutat.

En definitiva, amb el taller «Educar la mirada/Documentar la ciutat» hem trobat una forma de construir cartografies urbanes que representen altres formes de vida, en comptes d'itineraris turístics per al consum, per a la qual cosa hem de fer ús de noves formes de narrar, representar i produir identitat. Tot això que ja van expressar Charles Baudelaire (1863) o Walter Benjamin (1927) construeix per a nosaltres un objecte d'estudi que anomenem el currículum de la ciutat, o el que és el mateix, una estructura de coneixements i dispositius culturals presents a la ciutat amb els quals el subjecte interactua constantment i que el construeixen com a ciutadà. Per tant, el taller esdevé una oportunitat per a posar en qüestió les pràctiques educatives institucionals instal·lades en la racionalitat dominant que donen l'esquena a l'experiència, per situar-nos en el conflicte i construir el coneixement a través de la relació entre saber, identitat i poder. En aquest sentit, no sols ens preocupa el tractament que es fa del currículum en la formació universitària, sinó sobretot la ciutat com a currículum, és a dir la ciutat com a forma material de la cultura. Per tant, la ciutat s'entendrà no només com a producte, sinó també fonamentalment com a procés i experiència de subjectivació i producció de saber. Davant d'això, ens trobem en un punt on s'obrin dues vies d'investigació: per un costat, continuar aprofundint en els nuclis problematitzadors del currí- 
culum de la ciutat $^{1}$ de la mà dels estudis crítics i postcrítics i, per un altre, anar definint, amb Eva Marichalar, el que hem anomenat una pedagogia de la deriva, a través d'un diàleg entre l'experiència del taller i el projecte Deriva $\mathrm{Mussol}^{2}$ del qual ella forma part.

\section{Referencias}

Baudelaire, Сн. (1995): El pintor de la vida moderna, Colegio Oficial de Aparejadores y Arquitectos Técnicos de Murcia, Murcia.

Benjamin, W. (2005): El libro de los pasajes. Celeste Ediciones, Madrid.

CAReri, F. (2002): El andar como práctica estética/Walking as an Aesthetic Practice, Land\&Scape, Barcelona.

Contreras, J. i N. Pérez de Lara (comps.) (2010): Investigar la experiencia educativa, Morata, Madrid.

Debord, G. (1999): La sociedad del espectáculo, Pre-textos, Valencia.

-(2000): Los «no lugares», espacios del anonimato: Una antropología de la sobremodernidad ( $\left.5^{\mathrm{a}} \mathrm{ed}\right)$, Gedisa, Barcelona.

Delgado, M. (2007): Sociedades Movedizas: Pasos hacia una antropología de las calles, Anagrama, Barcelona.

-(2011) El espacio público como ideologia, Catarata, Madrid.

Freire, P. (1970): Pedagogía del oprimido, Siglo XXI, Madrid.

-(1999): La educación en la ciudad, Siglo XxI, Madrid.

Marichalar, E. (2011): «Deriva Mussol: Caminar a la deriva com a experiència de recerca», Quaderns d'Educació Contínua, 28: pp. 110-123.

Martínez Bonafé, J. (2010): «La ciudad en el currículum y el currículum de la ciudad». A Gimeno, J. (ed.): El currículum y el sentido de la educación, Morata, Madrid.

1. Aquesta és via en què més hem treballat i podem destacar els següents treballs: Martínez, J. (2010) o Estrela, M. i Martínez, J. (2012) disponible en : <http://aprendeenlinea.udea.edu.co/revistas/index.php/educacionfisicaydeporte/article/view/905>.

2. Deriva Mussol és un projecte que va nàixer en 2012 a la ciutat de Vic que també pren la deriva com a eix per a provocar l'experiència i el diàleg. Eva Maricharar desenvolupa els seus estudis des d'una perspectiva educativa àmplia, interessada a explorar els marges que uneixen educació, creació i territori. Les dues iniciatives s'han desenvolupat paral lelament aquests anys i actualment treballem conjuntament al voltant de la pedagogia de la deriva. Més informació en: http://derivamussol.com o Marichalar, E. (2001). 
Morin, E. i altres (1994): «Carta de la transdisciplinaridad», Portugal. S. P.

SAntos, B. DE S. (2004): La Universidad en el siglo XXI. Para una reforma democrática y emancipadora de la Universidad, Editorial Miño y Dávila, Buenos Aires.

SEnNet, R. (1997): Carne y piedra: El cuerpo y la ciudad en la civilización occidental, Alianza Editorial, Madrid.

-(2011) El declive del hombre público. Anagrama, Barcelona.

TAdeu da Silva, T. (2001): Espacios de identidad: Nuevas visiones sobre el currículum, Octaedro, Barcelona.

Tello Robira, R. (2003): «La ciudad como escenario de representación cultural: prácticas urbanísticas de perpetuación». A NASH, M i D. Marre (eds.): Desafío de la diferencia, articulando género, raza y clase. Universidad del País Vasco, pp. 213-224.

Van Manen, M. (2003): Investigación educativa y experiencia vivida, Idea Books, Barcelona. 